Germans as usual, patient and persevering, are attacking the problems that are presenting themselves with the greatest energy. That their labours may not only be preserved but may also be readily accessible and that future inquirers may not have to hunt through many volumes and pages of journals largely devoted to collateral subjects, a journal has been established with the title of "Biochemische Zeitschrift" under the editorship of Professor C. Neuberg of Berlin and we have received the first and second parts which have been published in June of the present year. The topics the consideration of which will be embraced in the journal are various, the prospectus stating that the editor means to include physiological and pathological, as well as physical chemistry, the physiology of plants, bacteriology, inquiries into the nature of immunity, pharmacology, experimental pathology, veterinary investigations, agricultural work, and the like which offer a sufficiently wide field of research. Many leading names are to be found in the list of promised contributors, such as those of Bang, Blumenthal, Galeotti, Hamburger, Kumagawa, Liebermann, Mandel, Michaelis, Nernst, Salaskin, Starling, Traube, Vandevelde, and others ; those who particularly coöperate with Professor Neuberg being Buchner, Ehrlich, C. von Noorden, E. Salkowski, and Zuntz. The publisher is Julius Springer of Berlin and the price of each volume, which will consist of six parts, is $12 s$.

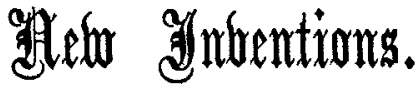

\section{A MODIFICATION OF LEITER'S URETHROSCOPE.}

IN common with many of my fellow surgeons I have for some years past been in the habit of using the instrument designed by Leiter of Vienna for illuminating the urethra. Although this instrument is admirable in many respects I have lately been using a modified form (vide illustration), and its superiority is so marked that I venture to bring it to the notice of my colleagues. The illumination (which when examining a dark red canal can never be too great) has been much increased by the juxtaposition of a high candle power lamp and a condensing lens which concentrates nearly all the light obtainable from one side of the

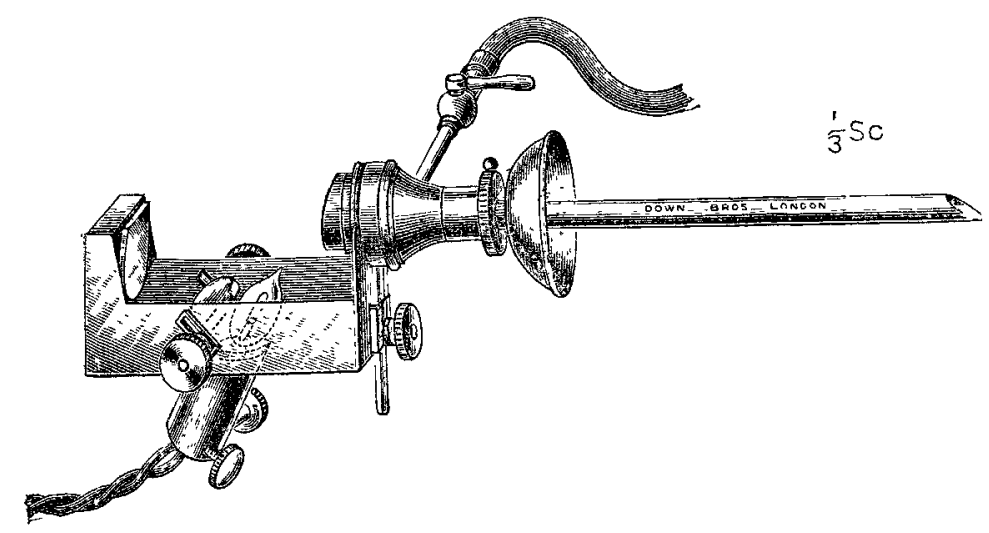

lamp upon the upper part of the reflecting mirror. This condensing lens greatly increases the amount of light obtainable and when used in conjunction with the special lamp and set at its proper angle and distance from the mirror gives such a strong white light that the texture of a piece of cloth or the convolutions on the skin of one's finger can be instantly and easily distinguished at the end of a long urethral tube. In Leiter's model only comparatively few of the diverging rays are utilised-viz., those which fall on a small area at the upper part of the mirror. In the new instrument the rays from one side of the lamp are concentrated on this spot by means of the lens. This area, which should be of about the size of a sixpenny-piece, should have one-third of the circle missing-i.e., the rays passing over the top of the mirror. The pattern of the pencil of light thrown into the cannula can easily be seen on the glass window of the nose-piece (it should be of a size slightly larger than the diameter of the urethral tube). The handle has been dispensed with, as in Fenwick's model, for although preferred by some for a simple examination it is better to grasp the body of the urethroscope when any instrumentation through the cannula is necessary. The cannula is thus much more under the direct control of the hand and the presence of the handle affects the balance and the delicacy of the manipulations. The square shape of the modified instrament affords a firmer hold and one of the projecting screws of the lens carrier, falling naturally between the first and second fingers of the hand, a perfect grip and balance are obtained. The mirror can be moved freely, and when the position reflecting the maximum illumination down the speculum has been found it can be fastened firmly in place by means of a small screw-head projecting behind it upon the back of the instrument and therefore well out of the line of sight. In the old model the mirror, which was usually kept more or less loose for focussing purposes, frequently moved whilst operating by its coming into contact with cotton-holders, forceps, \&c., thus plunging the part into darkness at a critical moment. All minor details have been carefully arranged. The window of the nose-piece, which now can be opened at will by a spring arrangement, was designed by me about ten years ago; it is now fitted to all Leiter's models, has the spring catch on the right side as the urethroscope is held with the left hand in all intra. urethral manipulations; the lamp has been obliquely placed and the filament arranged to obtain the best possible result. Those who have urethroscopes of Leiter's or Fenwick's pattern can have the condensing lens and special lamp fitted to them; the illumination is greatly increased by these means, and the lamps are quite inexpensive. 'The new instrument is fitted with von Antal's arrangement for distending the urethra with air. I would like to mention also that my friends to whom I have shown or lent the instrument have stated that they had hitherto been working in a comparatively dim light and that this illumination was quite a revelation to them. I have to thank Messrs. Down Brothers for so successfully carrying out my ideas and for producing an instrument which is not only simple and handy but practical and efficient, and which will go a long way towards popularising this method of treating chronic urethral diseases. W. Wrndham Poweld, F.R.C.S. Eng.

Cavendish-place, W.

\section{A NEW RETRACTOR.}

THIS retractor, made for me in two sizes by Messrs. White and Wright of Liverpool, is designed for use in pelvic operations but it may be of service in almost any abdominal procedure where the retraction of important organs is neces-

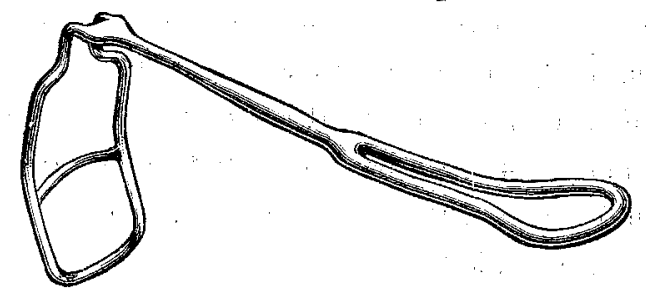

sary. It is very light, being made of stout wire, shaped as shown in the figure. I have found it very useful in holding forward the uterus to enable me to secure bleeding points in the pouch of Douglas after the removal of an adherent ovary and tube.

Liverpool.

W. BLair Bell, M.D., B S Lond.

SANATORIUMS FOR WORKERs.-On July 14th Princess Ohristian laid the foundation stone of the first sanatorium to be erected by the National Association for the Establishment and Maintenance of Sdnatoria for Workers suffering from Tuberculosis. The site of the building is at Benenden, Kent, where Her Rojal Highness was received by Mr. C. H. Garland, the chairman of the association, and by the honorary officers. In the course of the address to Her Royal Highness Mr. Garland stated: "The sanatorium is the first of what we hope will be a number, destined to supply the wants of the wor:ers who are suffering from tuberculosis. Apart from the accommodation for pauper cases there are not more than 3000 bed $s$ provided for the open-air treatment of consumption in this country. We have secured an estate of 250 acres and the present building is placed at a height of 230 feet above the sea level, on a slope that faces south-westward, and, as your Royal Highness is able to see, the outlook is extensive and beautiful. We are assured by our expert advisers that it fulfils all the essential requirements of a sanatorium site." The service was conducted by the Bishop of Dover. 